\section{NATURAL HISTORY \\ Drawing conclusions}

For millennia, people have observed, recorded and documented the living world and attempted to make sense of it. The Great Naturalists (Thames \& Hudson, 2007) charts the history of natural history through the lives of 40 such people over the past 2,000 years.

Alongside the expected names

- Aristotle, Linnaeus, Darwin - this handsome volume celebrates the lives and works of many lesser-known figures, including Konrad Gessner, the sixteenthcentury writer of Historia Animalium and Historia Plantarum, and Mary Anning, who discovered the first plesiosaur.

Four sections - 'The Ancients', 'The Renaissance', 'The Enlightenment' and 'The 19th Century' - all beautifully illustrated, often by the naturalists, show how the desire for striking

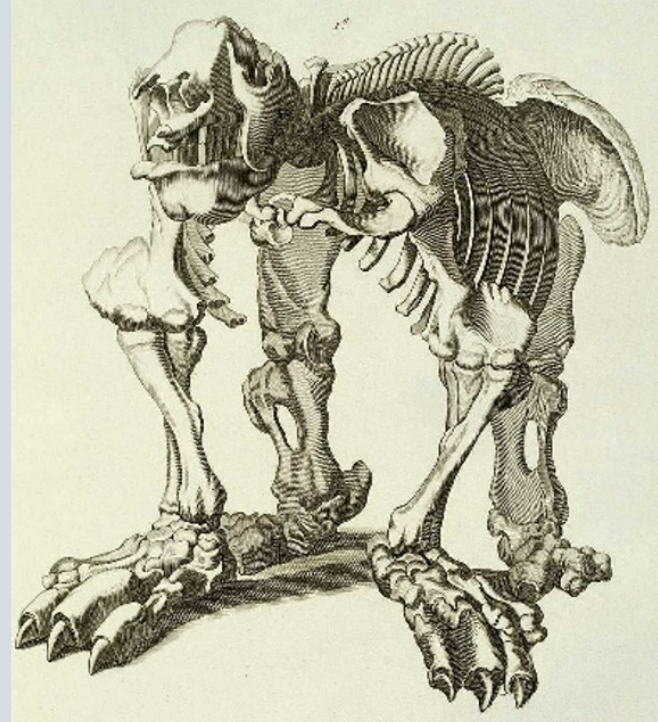

images collided with the need for accurate documentation. Pictured is Georges Cuvier's giant ground sloth (Megatharium) skeleton. Jenny Meyer

\title{
The greening of genomics
}

\section{Functional Plant Genomics edited by J. F. Morot-Gaudry, P. Lea \& J. F. Briat \\ Science Publishers: 2007. 699 pp. £69.88, $\$ 119.50$}

\section{Andrew H. Paterson}

A global investment in plant genomics is under way, thanks to increasing recognition of the services provided by higher plants to ecosystems. These plants fix the greenhouse gas carbon dioxide, enrich soil constituents and are valuable as a source of food, fuel, fibres and medicines.

We already know the genome sequences of thale grass (Arabidopsis thaliana), rice, the poplar tree and the grapevine, and those of papaya, sorghum and others are in the pipeline. The sequences of most crop genomes will probably be in hand in the next decade. These will seed "the birth of a new plant biology", a concept that forms the focus of Functional Plant Genomics and promises to expose relationships between DNA sequence and botanical diversity.
The book - edited by former leaders of the plant biology department at INRA, the French agricultural research agency - exceeds the scope of its title. It reaches from the ancestry of genomics, through genome sequencing, annotation and functional dissection, to translation of functional information from botanical models into crop improvement. The section on structural genomics includes results from classical cytogenetics and renaturation kinetics research. The findings have shaped our understanding of genome organization, from cloning and sequencing to the computational techniques that convert sequences into information. Included are intuitive explanations of basic methodologies along with detailed coverage of knowledge and resources.

Complete or exhaustive sequencing is addressed in detail. The authors note that "the cost of a complete sequence ... in the future will have to be balanced against the [pro]portion of specific information", but coverage of advances in whole-genome shotgun (equated to "partial zz or draft-type") sequencing is brief.

The section on functional genomics considers large-scale approaches to quantifying gene function, as reflected by phenotype, expression of messenger RNA, and protein and metabolite levels. It also gives some attention to the statistical methods used to extract signals from these (often noisy) data. Metabolomics features prominently. There is a particularly interesting chapter on the application of in silico metabolic mapping to complement and accelerate the deduction of pathways that are followed by each molecule entering an organism.

A final short section on genomics and technology is an extension of metabolomics. It details metabolic fingerprinting for developmental, genetic and stress-induced variations, as well as the self-assembly (and potential for manipulation) of biopolymers that determine the quality and utility of plant products.

Functional Plant Genomics gives specific attention to the many manifestations of botanical diversity. It evaluates models that range from small genomes such as $A$. thaliana, with its experimental expediency and extensive infrastructure, to complex large genomes of plants such as sugarcane (dear to my heart), the world's number-one biofuel crop.

How can hard-won functional information best be applied to crop improvement through plant breeding? The book takes on this question by assessing DNA-marker types (including those derived from transposable elements), quantitative trait locus mapping, and approaches based on candidate genes and association with determinants of a trait. There is discussion of progress in utilization of genomics for breeding two very different cereals, maize (corn) and wheat. Maize uses cross-pollination and has two sets of chromosomes; wheat is self-pollinating with six sets of chromosomes.

Minor errors and omissions notwithstanding, Functional Plant Genomics should broaden the perspective of researchers and postgraduate students on the role of genomics in the life sciences. Others will appreciate its glossary in what has become a fast-moving field pervaded by jargon.

Andrew $\mathrm{H}$. Paterson is a distinguished research professor and director at the Plant Genome Mapping Laboratory, University of Georgia, Athens, Georgia 30602, USA.
Invertebrate Neurobiology

edited by Geoffrey North and Ralph J. Greenspan (Scion, Cold Spring Harbor Laboratory Press: 2007. £65.34, \$135)

This monograph brings together two groups of scientists - molecular geneticists who study invertebrate organisms such as Caenorhabditis elegans and Drosophila, and classical ethological entomologists.

Invertebrate nervous systems are testament to the impressive range of solutions animals have evolved to live in all kinds of niches. The essays play on this diversity to illustrate molecular and cellular mechanisms of neural function, and higher-level circuits and systems.

Topics include 'Optic flow processing in the cockpit of the fly'; 'Insect walking'; 'Memories of worms and flies: From gene to behavior'; and 'Neuroendocrinology of eclosion'.

As Greenspan says, a lack of neuroanatomical homology with vertebrates may belie a deeper commonality in network architecture and in interactions among brain regions. The book assesses the universality of brain mechanisms and cognitive features, providing some useful pointers to what researchers studying vertebrate systems can learn from invertebrates.

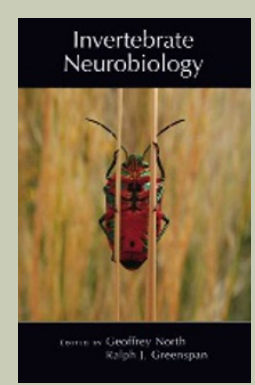

